\title{
The Effect of Dynamic Assessment on Iranian IELTS Students' Metacognitive Awareness for Reading Strategy and Reading Development
}

\author{
Maria Shobeiry \\ PhD Candidate University of Tehran \\ Department of Applied Linguistics
}

\begin{abstract}
This study investigated the effect of dynamic assessment (DA) on reading comprehension development and metacognitive awareness for reading strategies of Iranian IELTS students within the framework of Poehner (2008) who advocated the integration of assessment and instruction in promoting learners' abilities. It was a pretest-treatment-posttest quasi-experimental design in which 71 men and women advanced EFL learners participated. The experimental group $(n=35)$ received DA interventions for the period of 10 weeks ( 40 hours in total) and the control group $(\mathrm{n}=36)$ went through regular teaching methods and static assessment. Two academic IELTS reading comprehension equivalent tests were employed as the pretest and posttest. Also, the metacognitive awareness for reading strategy questionnaire of Mokhtari and Richard (2002) was administered twice (once at the outset and once at the end of the study). The results of an ANCOVA analysis showed that the experimental group outperformed the control group in reading comprehension development. Moreover, a statistically significant difference was found between the metacognitive awareness for reading strategies of the experimental group and that of the control group through the repeated measure AVONA test. Regarding the results, this study recommends teachers and IELTS instructors to consider DA in their test preparation programs. Keywords:Interventionist dynamic assessment; zone of proximal development; static assessment; reading comprehension.
\end{abstract}

DOI: $10.7176 /$ JLLL/79-02

Publication date:May $31^{\text {st }} 2021$

\section{Introduction}

International English Language Testing System (IELTS) is one of the most leading English proficiency tests in the world that plays a gatekeeping role for educational institutions in English speaking tertiary programs. Therefore, various IELTS preparation programs, in all over the world, attempt to help students get through this high-stakes testing system. To achieve this goal, language schools hold TTC (teacher training course) programs for IELTS instructors on a regular basis to improve their teaching strategies so that they could help test-takers fulfill their objectives optimally.

For years, in the history of education, teaching and assessment were considered as two separate entities. The main point of traditional assessment was to measure the learners' final achievement or performance without considering the learning potential of the test takers. Even today, despite the advent of complicated e-testing programs, assessment systems mainly provide the test takers with a general idea about their final achievement by illustrating their weaknesses and strengths as the main point of the assessment. They too consider assessment as a separate practice from teaching procedures.

Among the various methods of assessment introduced and applied in the area of language teaching and learning static assessment and dynamic assessment are the most well-known assessment approaches. Static assessment (SA hereafter) which is also known as traditional assessment method is measuring the product of the learning process and is mainly product-oriented; however, dynamic assessment (DA hereafter), which is based on Vygotsky's(1978) sociocultural theory, is a method of measuring the learning potential of the students during the teaching practice; so, it is predominantly process-oriented.

DA is relatively a new concept in language teaching programs with the main purpose of integrating assessment and teaching procedures (Tabatabaei\& Bakhtiarvand , 2014). In other words, DA is designed to investigate how students respond to instructions during the assessment procedure. Therefore, for example, when measuring learners' reading proficiency, the main emphasis of DA is on the students' learning potential as defined by Vygotsky as the Zone of Proximal Development (ZPD hereafter) which is the learners' cognitive zone in which they can perform a task with the support of the instructor (Poehner,2009).

The main problem with SA and traditional assessment systems is that they are not in keeping with human cognition potential during the learning process. This means that in order to elevate the instructors' quality of teaching and learners' final achievements, the learners' performance should be assessed based on how they represent knowledge and develop their abilities during the learning procedure (Anton, 2009; Poehner,2009; Tabatabaei\& Bakhtiarvand , 2014). 
Taking the previous ideas into consideration, the objective of this paper is to investigate the influence of DA on reading comprehension development of the EFL leaners and their metacognitive awareness for reading strategies compared to influence of the traditional SA system. In the following section some studies on these issues in the literature are reviewed.

\section{Review of the literature}

In this section first the literature is reviewed on the concept of dynamic assessment (DA) and the effect of DA on language learning; then, metacognitive strategies and metacognition in language learning are reviewed respectively.

\subsection{Dynamic assessment}

In order to review the research on various aspects of DA in the literature, it seems essential to first elaborate on the concept of DA and its difference from the traditional assessment methods to achieve a clear understanding of $\mathrm{DA}$ in education.

DA takes into consideration the developmental procedures of the learners during the teaching practice which is grounded in the theory of mental development of human being and Zone of Proximal Development (ZPD) introduced by the Russian psychologist Vygotsky (1987) who defined ZPD as the distance between what a learner can do without any help and what they can do with the support and help from a more knowledgeable person (Lantolf \& Poehner, 2010). Therefore, DA offers a conceptual framework which integrates assessment into instruction and considers learners' responsiveness to instruction as a measure of their learning potential (Anton, 2009; Saniei, Birjandi, \& Abdollahzadeh, 2015). This scaffolding practice, provided by teachers, is the essential characteristic of DA which is considered as the main role of teachers in this measurement methodology with the purpose of increasing learners' proficiency throughout the assessment procedure (Tabatabaei \& Bakhtiarvand , 2014).

In this sense, the clear difference between DA and SA is that SA can only measure the learner's actual level of performance and what they can perform independently; while, DA can measure the learners' potential level of performance (Fatemipour \& Jafari,2015). In other words, DA can measure the learners' future performance based on their cognitive developmental process which is the construct that can never be measured by SA.

According to the various contexts in which ZPD is discussed, two main approaches to DA is defined in the literature. The first approach is the interactionist DA which roots in Vygotsky's qualitative interpretation of ZPD in which the instruction-learning procedure is the center of the practice rather than the measurement process (Feuerstein, Rand, \& Hoffman; 2003). The second approach is the interventionist DA in which the main focus of the idea is on psychometric orientations toward pedagogy. The interventionist approach takes a quantitative perspective with a framework of pretest-intervention-posttest in experimental studies. The role of teachers in this approach is to cooperate with the learners during the teaching practice to improve the ability which is being assessed (Haywood \& Lidz 2007).

Among the studies employed the interventionist DA in the literature, the study of Birjandi, Estaji, and Deyhim (2013) is the closest to the purpose of my study in that they explored the effect of DA on reading comprehension development and metacognitive awareness for reading strategies of 47 female teenager intermediate EFL learners in Iran and revealed that DA was significantly effective on the development of intermediate learners' reading proficiency. However, they did not find any significant difference between the control and the experimental groups in terms of the effect of DA on metacognitive awareness for reading strategies of the learners. Another study conducted on Iranian teenage intermediate EFL learners was performed by Abdolrezapour (2016) to explore the effect of emotional DA on the participants' reading proficiency development. She mostly focused on the influence of using emotional intelligence characteristics as a tool for motivating adolescent learners while performing their reading tasks. To do this, she compared three groups of a) the control group who received no DA, b) the experimental group who received emotional DA, and c) the comparison group who received pure DA. Her results revealed that the participants who underwent the emotional DA during the reading assessment tasks performed significantly better than the participants who received the pure DA or no DA at all.

To explore the effect of DA on reading proficiency progression of adult EFL learners, Ajideh and Nourdad (2012) performed a research on Iranian university students' in L2 reading comprehension course across different levels of language proficiency. Their results confirmed a noticeable positive effect of DA on improving reading proficiency of the participants. Similar to the positive effect of DA on reading skill, DA was shown to have a positive effect on vocabulary achievement of intermediate EFL learners in the study of Hessamy and Ghaderi (2014) in a pretest- treatment-posttest experimental design.

With regard to the speaking skill, the results of Levi's (2016) study on the effect of DA on the extent of success of English language test preparation programs demonstrated a noticeable positive effect of DA on 
preparing Israeli high school students for the matriculation Oral Language Proficiency (OLP) test. Similarly, DA was found to be significantly effective on speaking development of upper intermediate IELTS students who participated in a case study, conducted by Minakova (2020), during a three-week DA mediation program. Her results revealed an evident effect of DA on the learners' control over the use of verb tenses in the speaking tasks of the IELTS exam.

With regard to the writing skill, Alavi and Taghizadeh (2014) explored the effect of DA and three types of implicit and explicit feedback on the essay writing of 32 Iranian male and female English language learners. Their results revealed that language learners were of various ZPDs with regard to their noticing and writing skill strategies and DA was confirmed to be a positively influential factor in improving internalization of writing content and organization skills and strategies in the participants. They also showed that teachers' mediation in the form of explicit feedback was the most effective hint within the dynamic assessment procedures. A long with these results, the effect of DA on writing development of Iranian EFL learners was also investigated by Rashidi and Bahadorinejad (2018) who showed a significant positive effect of DA on L2 writing progression of adult language learners whom received a DA treatment in three steps of topic-choice, idea generation, and macro-revising. These results were also supported by the results of an interview conducted at the end of their study which presented a positive effect of DA on learners' confidence in L2 writing. Similarly, Ebadi and Rahimi (2019) explored the effect of DA on writing proficiency development of academic IELTS students in Iran by conducting an online DA intervention program. They also performed a semi-structured interview at the end of the program to explore the students' perception toward the DA treatment. Their results presented a noticeable improvement in the writing proficiency of the participants in terms of task achievement, coherence and cohesion, lexicon, and grammatical range and accuracy. Furthermore, the outcome of the interview highlighted the learners' positive perception toward the impact of DA on their writing proficiency development.

Even though the results of the previous studies supported the positive effect of DA on writing development of the learners, the study of Hidri (2019) claimed no significant effect of DA on L2 writing development of advanced Omani college EFL learners in a mixed method research design. He stated that DA did not advance test-takers' current level of cognition into a more developed level nor did it predict better cognitive modifiability in the process of dynamic teaching of writing. Congruently, the study of Khodabakhshi, Abbasian, and Rashtchi (2018) displayed no significant effect of DA on the cognitive and metacognitive strategies used by EFL learners in writing classes. They conducted a mixed method research on the effect of interactionist and interventionist DA on language awareness and metacognitive strategy used by the participants and revealed that DA caused a higher level of language awareness in the participants without having any effect on their metacognitive strategy use in the learning process.

\subsection{Metacognitive strategies in language learning}

Metacognitive strategies in pedagogy are defined as thinking about the learning process, planning, monitoring, and evaluating the learning practice which direct and regulate the whole learning procedure $\left(\mathrm{O}^{\prime}\right.$ Malley \& Chamot, 1990). In other words, metacognitive strategies include developing problem solving skills, experimenting familiar and unfamiliar learning strategies, decision making about how to approach a task, selfmonitoring and self-evaluation, transferring successful test taking strategies to a new context, and enabling students to become more independent, autonomous, and lifelong learners (Oxford, 2003).

Some scholars suggested a more significant role for metacognitive learning strategies than other learning strategies in increasing language learners' overall performance (Nelson, 1996; Anderson, 2003; Oxford, 2003) in that once the learners understand how to regulate their own thoughts, their language acquisition proceeds at a faster rate (Nunan, 1996). This fact accentuates the crucial role of metacognitive awareness of the students in their L2 learning procedure. Put it differently, more proficient language learners are found to have greater metacognitive knowledge about their own thinking and learning skills which enables them to apply the most suitable learning strategies on a certain task in a learning context (Zhang \& Goh, 2006).

Developing metacognitive awareness in language learners leads them to success in language learning and testing procedures since it provides them with excessive knowledge about their own learning practice and information retrieval procedure (Goh, 2008). Metacognitive awareness enables language learners to monitor their own performance, find solutions to problems, and evaluate themselves on a task (Zhang \& Goh, 2006).Considering the importance of metacognitive awareness and strategies in language learners' overall performance, teachers should strive to develop students' metacognitive skills and teach them how to use these strategies in approaching a task (Goh, 2008).

Metacognitive strategies stem from a construct named metacognition which was first introduced in cognitive psychology in the 1960s (Nelson, 1996). Metacognition is defined as thinking about thinking or the ability to consciously think about mental processes (Nelson, 1996; Wenden, 1998).Another definition of metacognition is proposed by Flavell (1976) as “one's knowledge concerning one's own cognitive processes and products or anything related to them, e.g., the learning-relevant properties of information or data" (p. 232). 
Therefore, Metacognition is a form of cognition at a higher level of thinking that involves actively controlling cognitive actions (Wenden, 1998). Later in the literature, metacognition is even considered as the "seventh sense" in the learning practice (Birjandi et al. 2006).

It is worth noting that metacognitive knowledge and metacognitive strategies are defined in the literature as two distinct components of the term metacognition (Brown, 1983). The information a learner acquires about learning process is defined as metacognitive knowledge and the general skills through which a learners manages, directs, and regulates the learning procedure is termed as metacognitive strategies (Oxford, 2002).

Metacognitive awareness has been confirmed to be extensively influential in the process and outcome of learning in various subjects in pedagogy (Boekaerts, Pintrich, \& Zeidner, 2000; Bolitho et al., 2003; Eilam \& Aharon, 2003; Mokhtari \& Reichard, 2002; Palmer \& Goetz, 1988; Victori \& Lockhart, 1995; Zimmerman \& Schunk, 2001; Purpura, 1997, 1998).

In the realm of language learning, as Flavell (1979) stated, by invoking metacognitive awareness in language learners overall performance of the learners will improve ( Flavell ,1979). To confirm these statements, Salehi and Farzad (2003) revealed a positive relationship between metacognitive knowledge, learning conception, and language learning of the participants by employing the state metacognition inventory of O'Neil and Abedi (1996), learning conception interview based on Saljo's study (1979), and a researcher-made English language proficiency test as their data collection instruments. Their results showed a significant difference between weak and strong students in metacognitive awareness and their conception of learning; however, they did not elaborate on the type of difference in their discussion. The study of Zare and Sarmadi (2004) is worth noticing here since they investigated the difference between weak and strong university students in their metacognitive knowledge and metacognitive strategy awareness. They employed two researcher-made questionnaires with regard to metacognitive knowledge and metacognitive strategies to BA students and showed that learners' metacognitive knowledge and metacognitive awareness positively influenced both weak and strong students' academic achievement. The positive relationship of metacognitive awareness and academic achievement of language learners is also confirmed in the study of Javadi, Keyvanara, Yaghoobi, and Ebadi (2010) on Iranian university students in Isfahan. Similarly, metacognitive awareness of the language learners were found to be positively effective on their listening proficiency improvement in the study of Rahimi and Katal (2011).

\section{Significance of the study}

Since the positive effect of metacognitive awareness on language learners' achievement is confirmed in many studies in the literature (Boekaerts, Pintrich, \& Zeidner, 2000; Bolitho et al., 2003; Eilam \& Aharon, 2003; Salehi \& Farzad ,2003; Mokhtari \& Reichard, 2002; Palmer \& Goetz, 1988; Victori \& Lockhart, 1995; Zimmerman \& Schunk, 2001; Purpura, 1997, 1998; Ajideh \& Nourdad ,2012; Hessamy \& Ghaderi, 2014; Levi ,2016; Bahadori Nejad ;2018,Minakova, 2020), investigating the potential effect of DA on metacognitive awareness of language learners is of significant importance which has not been explored adequately in the literature of English language learning in general and Iranian EFL settings in particular.

In this regard, concerning the fact that DA is grounded in the cognitive developmental theory of Vygotsky (1978), its level of effectiveness on metacognitive awareness of the participants could be age-dependent. The only study on the effect of DA on metacognitive awareness for reading strategies of the Iranian EFL learners in the literature was performed by Birjandi et al. (2013) on teenage intermediate EFL learners which displayed no significant effect of DA on metacognitive awareness for reading strategies of the participants. There was no study in the literature to investigate the effect of DA on metacognitive awareness for reading strategies of the adult EFL learners prior to this research. Therefore, this study was an attempt to fill this gap in the literature by investigating the effect of DA on metacognitive awareness for reading strategies of adult Iranian language learners who were at the advanced level of language proficiency. Furthermore, with regard to the remarkable significance of IELTS preparation programs in the EFL courses in Iran, there is no study in the literature to investigate the effect of DA on reading proficiency improvement of IELTS test takers during a test preparation program.

\section{Theoretical framework and research questions}

This study is mainly based on the theoretical framework of Poehner (2008) on the concept DA who viewed DA as neither an assessment instrument nor a method of assessing; rather, a conceptual framework for teaching in which instruction and assessment are integrated as a unified body in pedagogy. In this framework, DA is an instrument to explore the learners' cognitive needs during the learning process. In other words, employing DA in pedagogy represent the unification of theory and practice during the learning procedure. In this sense, as Vygotsky (1978) stated, theory offers a basis to guide practice and practice functions to refine and extend the theory.

Furthermore, a quantitative approach to DA which involved a pretest-intervention-posttest design ( also known as the sandwich design for DA ) is the most practical framework for the purpose of this study in that the 
mean differences between the pretests and posttests of the participants would indicate the effectiveness of the DA intervention treatment during the instructional procedure (Haywood \& Lidz, 2007).It is worth mentioning that in this study group dynamic assessment (G-DA) was applied which, as Poehner (2009) demonstrated, follows the same principles and theories as individual DA to help the instructor reach an understanding about the whole group's ZPD.

Therefore, within this theoretical framework, this study responds to the following research questions:

1. Does dynamic assessment in IELTS preparation courses result in better reading comprehension performance of the advanced Iranian IELTS test takers?

2. Does dynamic assessment lead to a higher level of metacognitive awareness for reading strategies in the advanced IELTS test takers in comparison to static assessment?

\section{Methods}

\subsection{Participants}

Subject of this study comprised of 71 men and women advanced English learners who took a reading comprehension preparation course for the academic IELTS exam in January 2021. All the classes were held online on the e-learning platform of a language institution in Tehran whose name is not mentioned here due to the request of the main principal.

The age range of the participants was between 23-41 who majored in genetics, civil engineering, water resources engineering, nursing, applied physics, organic chemistry, microbiology, and clinical psychology.

They all had taken the online Cambridge Proficiency Test prior to their enrolment in this course; so, the homogeneity of the participants was ensured.

\subsection{Research design}

This study was a quasi-experimental research with the outline of pretest-treatment-posttest design in which two homogeneous intact groups were chosen as the experimental group $(n=35)$ and the control group $(n=36)$. The experimental group received the treatment of DA intervention for the period of ten weeks ( 2 sessions a week each session for 2 hours ); while, the control group did not receive any DA treatment during this time. All of the participants emailed me their letters of consent to participate in this study at the outset of the course; but, in order to increase the internal validity of the results and control for the internal threats of diffusion and subject effect, none of the participants knew which group was the experimental and which was the control group.

Reading tasks of the Official IELTS Practice Materials and Cambridge IELTS 14 Academic Student Books were studied in the online teaching sessions for the both groups. In order to control for the internal threat of the researcher's bias to validity of the results, the researcher was only the instructor of the control group. For the experimental group, another teacher of the institution was chosen who was trained on how to perform the DA interventions during the course.

Since all sessions were held online and automatically recorded on the e-learning platform of the institution, the recorded sessions of the experimental group were checked by the researcher for the quality of the provided DA treatments and exploring the learners' needs based on their developmental procedure after each session. The continual cooperation of the experimental group's teacher with the main researcher made all these procedures occur successfully throughout this study.

\subsection{Instrumentation}

Four instruments were employed for the purpose of this study, including: the Cambridge Online Proficiency Test, an academic IELTS reading task as the pretest and its equivalent as the posttest, a metacognitive awareness for reading strategy questionnaire, and a pamphlet of reading strategies for DA treatments.

\subsubsection{Cambridge online proficiency test}

The Cambridge proficiency test, comprised of 25 multiple-choice questions, was administered to all of the language learners by the institution prior to their enrolment in any program. It was mandatory in order to make the most homogeneous classes at different levels of language proficiency. Through this system, the homogeneity of the experimental and control group was assured.

\subsubsection{Metacognitive awareness questionnaire}

The metacognitive awareness of reading strategy questionnaire which was originally developed and validated by Mokhtari and Richard (2002), illustrated in appendix 1, was used for the purpose of this study. This questionnaire was designed to assess adolescent and adult English language readers' metacognitive awareness and perceived use of reading strategies while reading academic materials. There were 3 strategy subscales in this questionnaire: global reading strategies, problem-solving strategies, and support reading strategies. These three types of strategies interact with each other in nature and impose an important impact on reading comprehension of an individual in general.

Responses to this questionnaire were based on a 5-point Likert-type scale ranging from 1 (almost never) to 
5 (almost always) revealing the degree of strategy use by the subjects. Respondents had to complete the questionnaire twice during this study, once after the pretest and once after the posttest.

\subsubsection{Academic IELTS reading test and the scoring system of it}

An academic IELTS reading test was administered as the pretest and an equivalent form of it was employed as the posttest in this study. The tests contained 40 questions in which each correct answer received one mark. Raw scores, obtained out of 40, were converted to the IELTS nine-band scale as shown in Table1. This scoring system is borrowed from the IELTS marking criteria. Pretest and posttest scores in this research were reported in whole and half bands.

Table1.Academic reading scoring system

\begin{tabular}{cc}
\hline Band score & Raw score out of 40 \\
\hline 5 & 15 \\
5.5 & $16-22$ \\
6 & 23 \\
6.5 & $24-29$ \\
7 & 30 \\
7.5 & $31-34$ \\
8 & 35 \\
8.5 & $36-39$ \\
9 & 40 \\
\hline
\end{tabular}

\subsubsection{Pamphlet of reading strategies and teaching framework}

The experimental group underwent 40 hours (20 sessions) of DA treatment before the posttest. To provide a strong DA framework for the experimental group a short pamphlet was designed and emailed to the participants. It contained definitions and examples for reading strategies of scanning, skimming, identifying main ideas, guessing words' meanings from the context, and making inferences. For each of the reading strategies in the pamphlet, some related activities were provided to help the participants deeply understand the strategies during the reading practice.

In order to control for the extraneous variables of diffusion and subject effect, this pamphlet was emailed to all of the participants (both the experimental and control groups) to minimize the sensitivity of the participants to the research procedure and research results. However, only the experimental group received the DA treatment in a subtle way where they simply thought of it as a part of regular teaching method. Through these controlling plans the acceptable internal validity of the research was obtained.

During the reading practice, the mediator provided required appropriate hints with regard to the abovementioned strategies for the experimental group. In order to adjust the hints to the ZPD of the learners the clues were provided from the most implicit to the most explicit form. This process is shown in Table 2 in detail. Since all of the teaching sessions were recorded by the e-learning platform of the institution, and with regard to the fact that the mediator was not the researcher of this study, the type of hints and DA mediations were analyzed by the researcher through reviewing the recorded files after each session. This analysis was crucial since it revealed if the provided DA fit the leaners' needs during the teaching practice. If the students could not answer a reading question item correctly even after the DA treatment, it would mean that the scope of the DA was beyond their ZPD. In this case, the learners' proficiency was neither developed nor was developing in their cognitive system. Conversely, if the strategies and hints helped the participants answer the item correctly, it was concluded that their reading skill was developing and the DA was positively influential.

Table 2. Stages of Instructor's Mediation in the Process of DA

\section{ZPD step 1 Pause no mediation}

When the student does not answer the reading question at first but $\mathrm{s} /$ he finds the answer without mediation by thinking more.

ZPD step 2 Implicit hint on reading strategy

When the student does not answer the reading question after a long pause so the teacher provides him/her with implicit clues on the proper reading strategy including scanning, skimming, identifying main ideas, guessing words' meanings from the context, and making inferences to get her/him find the answer.

ZPD step 3 Explicit hint on reading strategy

When the student does not answer the reading question after the implicit hint. In this case the teacher provides him/her with some explicit hints on what strategy should be used in that case and what $\mathrm{s} /$ he should focus on in answering the question.

ZPD step 4 The student does not get to the correct answer after the whole above-mentioned steps. In this case the scaffolding is above the ZPD of the student and is not effectual in the teaching process. 


\subsection{Data collection procedures}

Since the design outline of this study was pretest-treatment-posttest, the data were collected through three steps including: 1) pretest scores, 2) completed metacognitive awareness for reading strategies questionnaires before and after the DA treatment, and 3) post-test scores.

\subsubsection{Pretest administration step}

The scores of an academic IELTS reading comprehension test administered to the both groups accompanying the completed metacognitive awareness questionnaires by both the control and experimental groups, prior to the DA treatment, constituted the pretest data of this study.

\subsubsection{Treatment (intervention) step}

The treatment of this study included 30-35 minutes of DA interventions for the period of 20 sessions. The DA treatments mainly focused on various reading strategies which were introduced to the learners through the pamphlet at the outset of the study (described in section 5.2.4.). The treatment was provided by the teacher only on the experimental group with the aim of making the learners more aware of the required reading strategies for better reading comprehension skill. After each session, the teacher and the researcher reviewed the recorded session and analyzed the quality of the DA treatments in terms of matching with the ZPD of the learners in order to obtain the most desirable results. In contrast, the students in the control group received no DA treatment; so, they were only exposed to the regular teaching methods of the language school.

\subsubsection{Posttest administration step}

After the treatment step, an equivalent test of the pretest was administered to the both experimental and control groups to see to what extent the experimental group benefited from the DA treatment in comparison with the control group. Furthermore, the participants of the both groups were asked to complete the same metacognitive awareness questionnaire for the second time at this stage to reveal the extent to which the DA treatment made any probable difference in the metacognitive awareness for reading strategies of the experimental group.

\subsection{Data analysis and results}

To answer to the first research question, first an ANCOVA analysis was performed to control for any initial unwanted differences. As Table 3 presents, the results of the ANCOVA analysis confirmed the homogeneity of the variables. Also, Figure 2 illustrates the linear relationship between pretest and posttest variables.

Table 3.Tests of Between-Subjects Effects

Dependent Variable: posttest

\begin{tabular}{cccccc}
\hline Source & Type III Sum of Squares & df & Mean Square & F & Sig. \\
\hline Corrected Model & $16.345^{\text {a }}$ & 3 & 5.448 & 85.826 & .000 \\
Intercept & .043 & 1 & .043 & .682 & .412 \\
group & .007 & 1 & .007 & .113 & .737 \\
pretest & 13.222 & 1 & 13.222 & 208.285 & .000 \\
group * pretest & .001 & 1 & .001 & .017 & .896 \\
Error & 4.253 & 67 & .063 & & \\
Total & 3388.500 & 71 & & & \\
Corrected Total & 20.599 & 70 & & & \\
\hline
\end{tabular}

a. R Squared $=.794$ (Adjusted R Squared $=.784)$

Figure 2.distribution of the pretest and posttest variables.

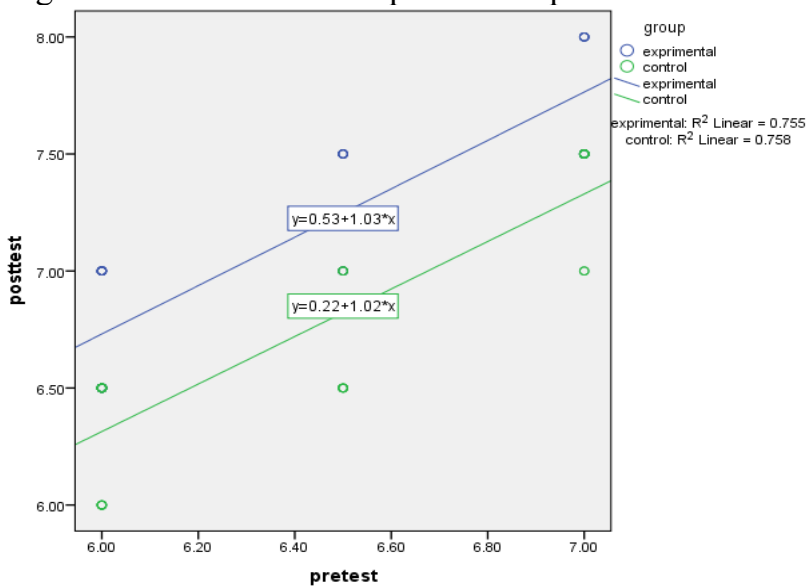

Furthermore, the results of the Leven's test revealed the acceptable equality of the standard deviations of the variables which confirms the homogeneity of the groups. 
Table 4. Levene's Test of Equality of Error Variances

Dependent variable: posttest

\begin{tabular}{cccc}
\hline F & df1 & df2 & Sig. \\
\hline 2.542 & 1 & 69 & .115 \\
\hline
\end{tabular}

Tests the null hypothesis that the error variance of the dependent variable is equal across groups.

a. Design: Intercept + pretest + group

More importantly, the results of the ANCOVA analysis revealed a statistically significant difference between the posttest and pretest variables in this study as is shown in Table 5 ( $F=50.87(p=0.00)$, partial Eta squared $=0.42$ ).

Table5.Tests of Between-Subjects Effects

\begin{tabular}{ccccccc}
\hline & Type III Sum of & & & & \multicolumn{2}{c}{$\begin{array}{c}\text { Partial Eta } \\
\text { Squared }\end{array}$} \\
\hline Source & Squares & df & Mean Square & F & Sig. & .793 \\
Intercept & $16.344^{\mathrm{a}}$ & 2 & 8.172 & 130.618 & .000 & .010 \\
pretest & .043 & 1 & .043 & .692 & .408 & .757 \\
group & 13.222 & 1 & 13.222 & 211.333 & .000 & .428 \\
Error & 3.183 & 1 & 3.183 & 50.875 & .000 & \\
Total & 4.254 & 68 & .063 & & & \\
Corrected Total & 3388.500 & 71 & & & & \\
\hline
\end{tabular}

a. R Squared $=.793$ (Adjusted R Squared $=.787$ )

As Table 6 shows, the mean of the experimental group is significantly higher than the mean of the control group; therefore, it can be concluded that the posttest results of the learners are significantly higher than their pretest results.

Table 6. Means of the dependent variable $=$ posttest

\begin{tabular}{lcrrr} 
& & & \multicolumn{2}{c}{$95 \%$ Confidence Interval } \\
\cline { 4 - 5 } group & Mean & Std. Error & Lower Bound & Upper Bound \\
\hline experimental & $7.102^{\mathrm{a}}$ & .042 & 7.018 & 7.186 \\
control & $6.679^{\mathrm{a}}$ & .042 & 6.595 & 6.762 \\
\hline
\end{tabular}

a. Covariates appearing in the model are evaluated at the following values: pretest $=6.3592$.

To answer to the second research question, a repeated measures ANOVA analysis is performed. Descriptive statistical analysis, displayed in Table 7, displays that the posttest results of the experimental group has significantly increased in comparison to the control group.

Table 7.Descriptive statistics of the variables

\begin{tabular}{lllcc}
\hline \multirow{2}{*}{ pretest } & group & Mean & Std. Deviation & $\mathrm{N}$ \\
& experimental & 6.3571 & .42997 & 35 \\
& control & 6.3611 & .42445 & 36 \\
\multirow{3}{*}{ posttest } & Total & 6.3592 & .42412 & 71 \\
& experimental & 7.1000 & .51163 & 35 \\
& control & 6.6806 & .49501 & 36 \\
& Total & 6.8873 & .54246 & 71 \\
\hline
\end{tabular}

The results of the Box's test, displayed in Table8, illustrates the homogeneity of the variables in the posttest and pretest scores. Furthermore, Levene's test of equality of error variances showed no significant difference; which also confirms the homogeneity of the variables (shown in Table 8).

Table 8.Box's Test of Equality of Covariance Matrices ${ }^{\mathrm{a}}$

\begin{tabular}{lc} 
Box's M & .076 \\
F & .024 \\
df1 & 3 \\
df2 & 880158.282 \\
Sig. & .995 \\
\hline
\end{tabular}

Tests the null hypothesis that the observed covariance matrices of the dependent variables are equal across groups.

a. Design: Intercept + group Within Subjects Design: factor1 
Table 9.Levene's Test of Equality of Error Variances ${ }^{\mathrm{a}}$

\begin{tabular}{rcrrr} 
& $\mathrm{F}$ & df1 & df2 & Sig. \\
\hline pretest & .025 & 1 & 69 & .874 \\
posttest & .181 & 1 & 69 & .672 \\
\hline
\end{tabular}

Tests the null hypothesis that the error variance of the dependent variable is equal across groups.

a. Design: Intercept + group

Within Subjects Design: factor1

The results of the multivariate test showed that the null hypothesis is rejected and the scores on the posttest have significantly increased in the experimental group.

Table 10.Multivariate Tests ${ }^{\mathrm{a}}$

\begin{tabular}{llcccccc}
\hline & Effect & Value & $\mathrm{F}$ & Hypothesis df & Error df & Sig. & Partial Eta Squared \\
\hline factor1 & Pillai's Trace & .825 & $324.215^{\mathrm{b}}$ & 1.000 & 69.000 & .000 & .825 \\
& Wilks' Lambda & .175 & $324.215^{\mathrm{b}}$ & 1.000 & 69.000 & .000 & .825 \\
& Hotelling's Trace & 4.699 & $324.215^{\mathrm{b}}$ & 1.000 & 69.000 & .000 & .825 \\
\multirow{3}{*}{ factor1 * group } & Roy's Largest Root & 4.699 & $324.215^{\mathrm{b}}$ & 1.000 & 69.000 & .000 & .825 \\
& Pillai's Trace & .427 & $51.507^{\mathrm{b}}$ & 1.000 & 69.000 & .000 & .427 \\
& Wilks' Lambda & .573 & $51.507^{\mathrm{b}}$ & 1.000 & 69.000 & .000 & .427 \\
& Hotelling's Trace & .746 & $51.507^{\mathrm{b}}$ & 1.000 & 69.000 & .000 & .427 \\
& Roy's Largest Root & .746 & $51.507^{\mathrm{b}}$ & 1.000 & 69.000 & .000 & .427 \\
\hline
\end{tabular}

a. Design: Intercept + group

Within Subjects Design: factor1

b. Exact statistic

Moreover, the results of the repeated measures ANOVA analysis, as shown in Table11 and Table 12, are proven to be strongly significant $(\mathrm{F}(68.1)=51.50, \mathrm{p}=0.00$, partial Eta squared $=0.42)$. In other words, we can confidently state that the posttest scores of the experimental group has significantly increased in comparison to the control group.

Table 11.Tests of Within-Subjects Effects

Measure: MEASURE 1

\begin{tabular}{|c|c|c|c|c|c|c|c|}
\hline Source & & $\begin{array}{l}\text { Type III Sum of } \\
\text { Squares }\end{array}$ & df & $\begin{array}{l}\text { Mean } \\
\text { Square }\end{array}$ & $\mathrm{F}$ & Sig. & $\begin{array}{c}\text { Partial Eta } \\
\text { Squared }\end{array}$ \\
\hline \multirow[t]{4}{*}{ factor1 } & Sphericity Assumed & 10.013 & 1 & 10.013 & 324.215 & .000 & .825 \\
\hline & Greenhouse-Geisser & 10.013 & 1.000 & 10.013 & 324.215 & .000 & .825 \\
\hline & Huynh-Feldt & 10.013 & 1.000 & 10.013 & 324.215 & .000 & .825 \\
\hline & Lower-bound & 10.013 & 1.000 & 10.013 & 324.215 & .000 & .825 \\
\hline factor1 & * Sphericity Assumed & 1.591 & 1 & 1.591 & 51.507 & .000 & .427 \\
\hline \multirow[t]{3}{*}{ group } & Greenhouse-Geisser & 1.591 & 1.000 & 1.591 & 51.507 & .000 & .427 \\
\hline & Huynh-Feldt & 1.591 & 1.000 & 1.591 & 51.507 & .000 & .427 \\
\hline & Lower-bound & 1.591 & 1.000 & 1.591 & 51.507 & .000 & .427 \\
\hline \multirow[t]{4}{*}{ Error(factor1) } & Sphericity Assumed & 2.131 & 69 & .031 & & & \\
\hline & Greenhouse-Geisser & 2.131 & 69.000 & .031 & & & \\
\hline & Huynh-Feldt & 2.131 & 69.000 & .031 & & & \\
\hline & Lower-bound & 2.131 & 69.000 & .031 & & & \\
\hline
\end{tabular}

Table 12.Tests of Within-Subjects Contrasts

Measure: MEASURE 1

\begin{tabular}{llcccccc} 
& & Type III Sum & & & \multicolumn{2}{c}{$\begin{array}{c}\text { Partial Eta } \\
\text { Squared }\end{array}$} \\
\hline factor1 & factor1 & of Squares & df & Mean Square & F & Sig. & .825 \\
factor1 * group & Linear & 10.013 & 1 & 10.013 & 324.215 & .000 & .427 \\
Error(factor1) & Linear & 1.591 & 1 & 1.591 & 51.507 & .000 & .031 \\
\hline
\end{tabular}

\section{Discussion}

The results of the statistical analysis illustrated a significant difference between the posttest and pretest scores of the participants. This means that the DA treatment had a significant positive effect on reading proficiency development of the experimental group compared to the control group. Moreover, a repeated measures ANOVA analysis showed that DA had a significant positive effect on metacognitive awareness for reading strategies of the experimental group. The results of this study supported the outcomes of Ajideh and Nourdad (2012), Birjandi et al. (2013), and Abdolrezapour (2016) in terms of the positive effect of DA on reading proficiency 
development of the participants. However, the results of this research were in contrast to the results of Birjandi et al. (2013) in that they presented no effect of DA on metacognitive awareness for reading strategies of the participants. Since the participants in the study of Birjandi et al. (2013) were intermediate high school teenagers and participants of this study were adult advanced EFL learners, the difference in the results could be, partly, due to the age range of the participants which needs to be investigated in further studies.

The results of this study also supported the findings of Levi (2016) and Minakova (2020) on the positive effect of DA on the success of the language proficiency preparation programs for high-stakes exams such as OLP (Oral Language Proficiency) in Israel or IELTS in all over the world. Since success in these exams are of great importance for students who desire to apply to study in English medium universities, the results of this study have noteworthy implications for EFL teachers who work in English proficiency exam preparation programs.

\section{Conclusion}

The DA intervention was found to be significantly influential in language learners' reading proficiency improvement and also in their metacognitive awareness for reading strategies during a ten-week reading comprehension course in this study. DA was confirmed to help students attain better understanding of the reading texts and achieve higher scores in the final IELTS mock test (posttest). The main implication for IELTS instructors and English teachers could be noticing the significant positive impact of DA on advanced IELTS students' reading progression during a short period of time (only 40 hours in ten weeks) through increasing their metacognitive awareness for reading strategies. The reason for this inference is that in many test preparation programs the effectiveness of the teaching methods is measured by the variable of time; meaning, the majority of the test takers are in a hurry to achieve the acceptable level of language proficiency as soon as possible. Therefore, this study revealed that DA should be considered as a pivotal teaching strategy in IELTS preparation programs.

\section{Appendix 1.}

Directions: Listed below are statements about what people do when they read academic or school-related materials such as textbooks or library books. Five numbers follow each statement $(1,2,3,4,5)$, and each number means the following:

- 1 means "I never or almost never do this."

- 2 means "I do this only occasionally."

- 3 means "I sometimes do this" (about $\mathbf{5 0 \%}$ of the time)

- 4 means "I usually do this."

- 5 means "I always or almost always do this."

After reading each statement, circle the number $(1,2,3,4$, or 5$)$ that applies to you using the scale provided. Please note that there are no right or wrong answers to the statements in this inventory.

\begin{tabular}{|c|c|c|c|c|c|c|}
\hline \multirow{2}{*}{$\frac{\text { Type }}{\text { GLOB }}$} & \multirow{2}{*}{$\begin{array}{r}\text { Strategy } \\
\text { 1. I have a purpose in mind when I read. }\end{array}$} & \multicolumn{5}{|c|}{ Scale } \\
\hline & & 1 & 2 & 3 & 4 & \\
\hline SUP & 2. I take notes while reading to help me understand what I read. & 1 & 2 & 3 & 4 & 5 \\
\hline GLOB & 3. I think about what I know to help me understand what I read. & 1 & 2 & 3 & 4 & 5 \\
\hline GLOB & 4. I preview the text to see what it's about before reading it. & 1 & 2 & 3 & 4 & 5 \\
\hline SUP & 5. When text becomes difficult, I read aloud to help me understand what I read. & 1 & 2 & 3 & 4 & 5 \\
\hline SUP & 6. I summarize what I read to reflect on important information in the text. & 1 & 2 & 3 & 4 & 5 \\
\hline GLOB & 7. I think about whether the content of the text fits my reading purpose. & 1 & 2 & 3 & 4 & 5 \\
\hline PROB & 8. I read slowly but carefully to be sure I understand what I'm reading. & 1 & 2 & 3 & 4 & 5 \\
\hline SUP & 9. I discuss what I read with others to check my understanding. & 1 & 2 & 3 & 4 & 5 \\
\hline GLOB & 10. I skim the text first by noting characteristics like length and organization. & 1 & 2 & 3 & 4 & 5 \\
\hline PROB & 11. I try to get back on track when I lose concentration. & 1 & 2 & 3 & 4 & 5 \\
\hline SUP & 12. I underline or circle information in the text to help me remember it. & 1 & 2 & 3 & 4 & 5 \\
\hline PROB & 13. I adjust my reading speed according to what I'm reading. & 1 & 2 & 3 & 4 & 5 \\
\hline GLOB & 14. I decide what to read closely and what to ignore. & 1 & 2 & 3 & 4 & 5 \\
\hline SUP & 15. I use reference materials such as dictionaries to help me understand what I read. & 1 & 2 & 3 & 4 & 5 \\
\hline PROB & 16. When text becomes difficult, I pay closer attention to what I'm reading. & 1 & 2 & 3 & 4 & 5 \\
\hline GLOB & 17. I use tables, figures, and pictures in text to increase my understanding. & 1 & 2 & 3 & 4 & 5 \\
\hline PROB & 18. I stop from time to time and think about what I'm reading. & 1 & 2 & 3 & 4 & 5 \\
\hline GLOB & 19. I use context clues to help me better understand what I'm reading. & 1 & 2 & 3 & 4 & \\
\hline SUP & 20. I paraphrase (restate ideas in my own words) to better understand what I read. & 1 & 2 & 3 & 4 & 5 \\
\hline PROB & 21. I try to picture or visualize information to help remember what I read. & 1 & 2 & 3 & 4 & \\
\hline GLOB & 22. I use typographical aids like boldface and italics to identify key information. & 1 & 2 & 3 & 4 & 5 \\
\hline GLOB & 23. I critically analyze and evaluate the information presented in the text. & 1 & 2 & 3 & 4 & \\
\hline SUP & 24. I go back and forth in the text to find relationships among ideas in it. & 1 & 2 & 3 & 4 & 5 \\
\hline GLOB & 25. I check my understanding when I come across conflicting information. & 1 & 2 & 3 & 4 & \\
\hline GLOB & 26. I try to guess what the material is about when I read. & 1 & 2 & 3 & 4 & 5 \\
\hline PROB & 27. When text becomes difficult, I reread to increase my understanding. & 1 & 2 & 3 & 4 & 5 \\
\hline SUP & 28. I ask myself questions I like to have answered in the text. & 1 & 2 & 3 & 4 & 5 \\
\hline GLOB & 29. I check to see if my guesses about the text are right or wrong. & 1 & 2 & 3 & 4 & 5 \\
\hline PROB & 30. I try to guess the meaning of unknown words or phrases. & 1 & 2 & 3 & 4 & 5 \\
\hline
\end{tabular}




\section{References}

Abdolrezapour, P. (2016). Improving L2 Reading Comprehension through Emotionalized Dynamic Assessment Procedures. Journal of Psycholinguistic Research, 46(3), 747-770. https://doi.org/10.1007/s10936-0169464-9

Ajideh, P., \& Nourdad, N. (2012). The Effect of Dynamic Assessment on EFL Reading Comprehension in Different Proficiency Levels. Language Testing in Asia, 2(4), 101. https://doi.org/10.1186/2229-0443-2-4101

Alavi, S. M., \& Taghizadeh, M. (2014). Dynamic Assessment of Writing: The Impact of Implicit/Explicit Mediations on L2 Learners' Internalization of Writing Skills and Strategies. Educational Assessment, 19(1), 1-16. https://doi.org/10.1080/10627197.2014.869446

Anderson, N. J. (2003). Metacognitive reading strategies increase L2 performance. The Language Teacher, 27, $20-22$.

Antón, M. (2009). Dynamic Assessment of Advanced Second Language Learners. Foreign Language Annals, 42(3), 576-598. https://doi.org/10.1111/j.1944-9720.2009.01030.x

Birjandi, P., Estaji, M., \& Deyhim, T. (2013). The Impact of Dynamic Assessment on Reading Comprehension and Metacognitive Awareness of Reading Strategy Use in Iranian High School Learners. Iranian Journal of Language Testing, 3(2), 60-77. http://www.ijlt.ir/article 114384.html

Birjandi, P., Mirhassani, A. \& Abbasian, G. (2006).Setting-based metacognitive strategy use.Journal of Faculty of Letters and Humanities, 49(198), 39-87. Available online: www.sid.ir.

Boekaerts, M., Pintrich, P., and Zeidner, M. (2000).Handbook of self-regulation. San Diego: Academic Press.

Bolitho, R., Carter, R., Hughes, R., Ivanic, R., Masuhara, H., \& Tomlinson, B. (2003). Ten questions about language awareness. ELT Journal, 57(3), 251-260.

Ebadi, S., \& Rahimi, M. (2019). Mediating EFL learners' academic writing skills in online dynamic assessment using Google Docs. Computer Assisted Language Learning, 32(5-6), 527-555. https://doi.org/10.1080/09588221.2018.1527362

Eilam, B., \& Aharon, I. (2003).Students' planning in the process of self-regulated learning. Contemporary Educational Psychology, 28, 304-334.

Fatemipour, H., \& Jafari, F. (2015). The Effect of Dynamic-Assessment on the Development of Passive Vocabulary of Intermediate EFL Learners. J. Educ. Manage. Stud., 5(1), pp. 41-51.

Flavell, J. H. (1976). Metacognitive aspects of problem solving. In L. B. Resnick (Ed.), The nature of intelligence. Hillsdale, NJ: Erlbaum.

Goh, C. (2008). Metacognitive instruction for second language listening development: Theory, practice and research implications. Regional Language Centre Journal, 39(2), 188-213.

Haywood H.C. \& Lidz C. (2007). Dynamic Assessment in Practice Clinical and Educational Applications. NY: Cambridge University Press.

Hessamy, G., \& Ghaderi, E. (2014). The Role of Dynamic Assessment in the Vocabulary Learning of Iranian EFL Learners. Procedia - Social and Behavioral Sciences, 98, 645-652. https://doi.org/10.1016/j.sbspro.2014.03.463

Hidri, S. (2019). Static vs. dynamic assessment of students' writing exams: a comparison of two assessment modes. International Multilingual Research Journal, 13(4), 239-256. https://doi.org/10.1080/19313152.2019.1606875

Javadi, M., Keyvanara. M., Yaghoobbi, M., Hassanzade, A., \& Ebadi, Z.(2010). The Relationship between metacognitive awareness of reading strategies and students' academic status in Isfahan University of Medical Sciences. Iranian medical science journal, 3(10).246-254.

Khodabakhshi, S., Abbasian, GH-R., \& Rashtchi, M. (2018). Incorporation of dynamic assessment models into developing language awareness and metacognitive strategy use in writing classes. Journal of Modern Research in English Language Studies, 4(5), 55-79. DOI:10.30479/JMRELS.2019.10826.1353

Minakova, V. (2020). Dynamic Assessment of IELTS Speaking: A Learning-Oriented Approach to Test Preparation. Language and Sociocultural Theory, 6(2), 184-212. https://doi.org/10.1558/1st.36658

Mokhtari, K., \& Reichard, C. (2002).Assessing students' metacognitive awareness of reading strategies. Journal of Educational Psychology, 94,249-259.

Nelson, T. O. (1996). Consciousness and metacognition. American Psychologist, 51, 102-116.

Nunan, D. (1996). Learner strategy training in the classroom: An action research study. TESOL Journal, 6(1), $35-41$.

O’Malley, J.M., Chamot, A.U., and Küpper, L. (1989).Listening comprehension strategies in second language acquisition. Applied Linguistics, 10, 418-37.

O'Neil, H. F., Jr., \& Abedi, J. (1996). Reliability and validity of a state metacognitive inventory: Potential for alternative assessment. The Journal of Educational Research, 89(4), 234245. https://doi.org/10.1080/00220671.1996.9941208 
Oxford, R. L.(2003). Language learning styles and strategies: An Overview. Oxford: GALA.

Palmer, D. J., \& Goetz, E. T. (1988). Selection and use of study strategies: The role of the studier's beliefs about self and strategies. In C. E. Weinstein, E. T. Goetz, and P. Alexander (Eds.), Learning and study strategies: Issues in assessment, instruction, and evaluation (pp. 77-100). Orlando, FL: Academic Press.

Poehner, M. E. (2009). Group dynamic assessment: Mediation for the L2 classroom. TESOL Quarterly, 43(3), 471-491. DOI: 10.1002/j.1545-7249.2009.tb00245.x

Purpura, J.E.(1997). An analysis of the relationship between test taker' congnitive and metacognitive strategy use and second language test performance. Journal of language learning 47 289-325.

Purpura, J. (1998). Investigating the effects of strategy use and second language test performance with high- and low-ability test-takers: A structural equation modeling approach. Language Testing, 15, 333-379.

Rahimi, M. \& Katal, M. (2010). Iranian university students' metacognitive listening strategies awareness in learning English. Paper presented at the third national conference on education, Tehran, Iran.

Rashidi, N., \& Bahadori Nejad, Z. (2018). An Investigation Into the Effect of Dynamic Assessment on the EFL Learners' Process Writing Development. SAGE Open, 8(2), 215824401878464. https://doi.org/10.1177/2158244018784643

Salehi, R., and Farzad, V.A.(2003). The relationship between metacognitive knowledge, learning conception and learning English. Journal of Psychology, 7(3), 270-286.

Saljo, R. (1979). "Educational Experience and Learning Performance: Some Observations." Paper Presented at the Third EARDHE Congress, University of Klagenfurt, 2-6 January.

Saneiei, A., Birjandi, P., \& Abdollahzadeh, E. (2015). On the practicality of group dynamic assessment: A seminal enterprise deserving closer scrutiny. International Journal of Applied Linguistics \& English Literature. 4(2), 39- 46.

Tabatabaei, S. \& Bakhtiarvand, M. (2014). Application of Dynamic Assessment in Second and Foreign Language Teaching. International Journal for Teachers of English, 4(3), pp. 1-14.

Victori, M., and Lockhart, W. (1995). Enhancing metacognition in self-directed language learning. System, 23 , 223-234

Vygotsky, L. S. (1978). Mind in Society: the Development of Higher Psychological Processes. Cambridge, MA: Harvard University Press.

Wenden, A. (1998). Metacognitive knowledge and language learning. Applied Linguistics, 19(4), 515-537.

Zare, H., \& Sarmadi, M.R.(1383). The difference between weak and strong Payame Nour University students in their metacognitive knowledge and metacognitive strategies awareness. Nour review, 3(2). Available online: www.sid.ir

Zimmerman, B. J., \& Schunk, D. H. (2001).Self-regulated learning and academic achievement. Mahwah, NJ: Erlbaum

Zhang, D., \& Goh, C. (2006). Strategy knowledge and perceived strategy use: Singaporean students' awareness of listening and speaking strategies. Language Awareness, 15,199-219. 